\title{
Production of bioethanol from apple pomace by using cocultures: Conversion of agro-industrial waste to value added product
}

\author{
Ezgi Evcan, Canan Tari* \\ Department of Food Engineering, Izmir Institute of Technology, Gulbahce Campus, TR 35430, Urla, Izmir, Turkey
}

\section{A R T I C L E I N F O}

\section{Article history:}

Received 11 August 2014

Received in revised form 1 April 2015

Accepted 13 May 2015

Available online 21 June 2015

\section{Keywords:}

Aspergillus sojae

Apple pomace

Bioethanol

Green process

Saccharomyces cerevisiae

Trichoderma harzianum

\begin{abstract}
A B S T R A C T
Direct fermentation of cellulosic biomass to bioethanol has been very promising and hence attracted attention in recent years. In this study, bioethanol production from apple pomace hydrolysate (agroindustrial waste product) was investigated by coculturing Trichoderma harzianum, Aspergillus sojae and Saccharomyces cerevisiae using statistical approaches. Screening and optimization experiments were conducted in order to determine the significant factors and their optimum levels for maximum bioethanol production. Inoculation rates, aeration and agitation speed were considered as factor variables and bioethanol production as response variable. Highest bioethanol $(\mathrm{EtOH})$ concentration and ethanol yield on total reducing sugar content $\left(\mathrm{Y}_{\mathrm{P} / \mathrm{S}}\right)$ were $8.748 \mathrm{~g} / \mathrm{L}$ and $0.945 \mathrm{~g} / \mathrm{g}$, respectively. Optimum conditions were $6 \%(\mathrm{w} / \mathrm{v})$ inoculation rates of Tharzianum and A.sojae, and $4 \%(\mathrm{v} / \mathrm{v})$ inoculation rate of S.cerevisiae with vented aeration method and agitation speed of $200 \mathrm{rpm}$. To best of our knowledge to date, no reports are available in literature regarding the coculturing of T.harzianum, A.sojae and S.cerevisiae for bioethanol production. Therefore, this study will serve as a base line of initial studies in this field. The method can create a renewable alternative feedstock for fossil fuel production and suggest a feasible solution to multiple environmental problems simultaneously creating a sink for waste utilization.
\end{abstract}

๑) 2015 Elsevier Ltd. All rights reserved.

\section{Introduction}

During the last decades the search for new alternative and renewable energy resources has increased rapidly, as a response to the increase in population that caused growing energy demand for transportation and industry and a huge consumption of limited fossil fuels. Dramatic raises in oil prices and global warming reached threatening limits. Hence, there has been a tremendous urge in extending the use of biofuels and biomass derived energy, since it can be obtained from sustainable resources [1]. Biomass, which refers to living and recently dead biological materials, is an infinite and renewable feedstock for production of biofuels [2]. However, in order to become a future alternative fuel source some properties are required. First of all, the potential candidate must decrease greenhouse gas emissions, decrease energy consumption, slow down global warming by capturing and storing $\mathrm{CO}_{2}$ and provide efficient energy utilization. Furthermore, its production

\footnotetext{
* Corresponding author. Tel.: +90 232 7506316; fax: +90 2327506196.

E-mail addresses: ezgihoser@iyte.edu.tr (E. Evcan), canantari@iyte.edu.tr (C. Tari).
}

technology must be clean with regard to the environment and be economically feasible [3]. Besides, non-food feedstocks can also be used in the production of alternative fuels in order to prevent some concerns and ethical problems related to their usage. Bioethanol proved itself as an attractive low-cost alternative to replace fossil fuels with its biorenewable nature carrying all of the features required.

Fruit juice industry is one of the biggest industries in the world that forms a large quantity of wastes, such as peel, seed, pomace, rags, kernels etc. In 2009, Europe produced 11.3 billion liters of fruit juice products followed by North America with 9.5 billion liters [4]. Apple pomace is one of the wastes resulting from the food industry and contains peel, seeds and remaining solid parts formed after juice extraction. Pomace represents approximately $25-35 \%$ of the weight of the fresh apple processed [5]. According to FAOSTAT (Food and Agriculture Organization of the United Nations Statistical Databases), total world production of apple was approximately 76 million tons by the year 2011 [6] and apple pomace constituted approximately 8 million tons [7] which causes important environmental problems. Due to its composition (richness in carbohydrates, dietary fibres and minerals, high fermentable sugar 
content), it holds a great potential to be used as raw material for the microbial production of value added products such as bioethanol. In fact pomaces are easy to obtain, harsh and expensive methods are not necessary. Within this context, utilization of apple pomace for production of bioethanol can lead the way of producing value added products from similar agro-industrial wastes and provide an alternative solution to the accumulation of waste of the fruit juice industry which is a primary environmental problem. The new technological improvements in biotechnology based on alternative biomass sources will play an important role in solving the problem related to growing energy demands.

S.cerevisiae is the most commonly used microorganism for bioethanol production because of its high production rate, but it cannot use xylose for fermentation which is one of the main sugars present in lignocellulosic biomass, especially in fruit pomaces. Various filamentous fungi, such as certain Trichoderma and Aspergillus species, have been reported to produce bioethanol as the main fermentation product from lignocellulosic biomass, directly $[8,9]$. These fungi are thought to contain two biological systems: one system produces cellulase enzyme for degradation of cellulose to fermentable sugars under aerobic conditions; the second system produces ethanol under anaerobic conditions [10]. However, although Trichoderma and Aspergillus are able to utilize five of the lignocellulosic sugars (glucose, mannose, galactose, xylose and arabinose) and the ability of direct fermentation of lignocellulose to bioethanol, they do not produce bioethanol with high yield and high rate. Therefore, in order to increase the fermentation yield, utilization of cocultures could be a convenient way of producing bioethanol from agricultural residues.

This study investigates the bioethanol production from apple pomace hydrolysate using the cocultures of T.harzianum, A.sojae and S.cerevisiae, in order to create a renewable and low cost alternative feedstock for fossil fuel production and to highlight a feasible solution to multiple environmental problems by reducing the accumulation of agro-industrial waste products.

\section{Materials and methods}

\subsection{Apple pomace and its hydroylsation}

Apple pomace, composed of almost just peels of approximately $1 \mathrm{~cm}^{2}$ particles, was obtained from "Konfrut Fruit Juice Concentrates and Purees, Denizli, Turkey" in ice bags and stored until usage at $-20^{\circ} \mathrm{C}$ in plastic packages. It did not require any chopping before use.

According to previous studies conducted by Ucuncu et al. [11], temperature of $110{ }^{\circ} \mathrm{C}, 40 \mathrm{~min}, 4 \%$ phosphoric acid and $1: 10$ solid/ liquid ratio $(\mathrm{w} / \mathrm{v})$ were determined as optimum hydrolysis conditions of apple pomace. Hydrolysates were filtered, $\mathrm{pH}$ was adjusted to 5.0 , using $6 \mathrm{~N} \mathrm{NaOH}$ and sterilized at $121{ }^{\circ} \mathrm{C}$ for $15 \mathrm{~min}$.

\subsection{Microorganism and media}

Total of three strains, two fungi and one yeast were used in fermentation experiments. The fungal strains, T.harzianum NRRL 31396 and A.sojae ATCC 20235, were kindly provided by Paul J. Weimer from USDA-ARS-US Dairy Forage Research Center, Madison, United States and from Food Engineering Department of İzmir Institute of Technology (IZTECH), Izmir, Turkey, respectively. The yeast, S.cerevisiae NRRL Y-139, was obtained from Molecular Biology Laboratory of IZTECH.

T.harzianum was incubated at $30{ }^{\circ} \mathrm{C}$ until well sporulation $(5-7$ days) on Malt Extract Agar (MEA) petri dishes and slants containing (g/L): malt extract, 30; peptone, 3; and agar, 15 . The pre-activation of A.sojae cultures was done on YME (Yeast Malt Extract) agar medium containing (g/L): malt extract, 10; yeast extract, 4; glucose, 4; and agar, 20 and activation in molasses agar slants containing ( $\mathrm{g} /$ L): glycerol, 45; molasses, 45; peptone, $18 ; \mathrm{NaCl}, 5$; agar, 20; and stock solutions (mg/L): $\mathrm{FeSO}_{4} .7 \mathrm{H}_{2} \mathrm{O}, 15 ; \mathrm{KH}_{2} \mathrm{PO}_{4}, 60 ; \mathrm{MgSO}_{4}, 50$; $\mathrm{CuSO}_{4} \cdot 5 \mathrm{H}_{2} \mathrm{O}, 12$; and $\mathrm{MnSO}_{4} \cdot \mathrm{H}_{2} \mathrm{O}, 15$ ) incubated at $30{ }^{\circ} \mathrm{C}$ for one week (until well sporulation). Spores of both T.harzianum and A.sojae were harvested using $5 \mathrm{ml}$ of Tween 80 -water $(0.02 \% \mathrm{v} / \mathrm{v})$ and collected in sterile falcon tubes. Spore counts were performed using Thoma bright line haemocytometer (Marienfield, Germany). S.cerevisiae was propagated at $30^{\circ} \mathrm{C}$ for $48 \mathrm{~h}$ on YPD (Yeast ExtractPeptone-Dextrose) media containing \% (v/v): glucose, 2; peptone, 2; yeast extract, 1 ; and agar, 2 . A loop-full of $48 \mathrm{~h}$-old single colony was transferred from a fresh YPD agar plate into $250 \mathrm{~mL}$ Erlenmeyer flask containing $50 \mathrm{~mL}$ of YPD broth media and incubated at $30{ }^{\circ} \mathrm{C}$ and $150 \mathrm{rpm}$ in basic orbital shaker for $48 \mathrm{~h}$, in order to construct the growth curve by measuring the viable cell counts and optical densities using a Varian Cary Bio 100 spectrophotometer at $600 \mathrm{~nm}$.

\subsection{Fermentation}

\subsubsection{Aerobic growth}

A.sojae was grown in $250 \mathrm{~mL}$ Erlenmeyer flasks containing $50 \mathrm{~mL}$ molasses broth media. Initial spore count was adjusted to approximately $1 \times 10^{7}$ spore $/ \mathrm{mL}$ and used for the inoculation of the flasks which were incubated at $30{ }^{\circ} \mathrm{C}$ in a $200 \mathrm{rpm}$ rotary shaker based on a study conducted by Skory et al. [9]. Incubation time was determined as $48 \mathrm{~h}$ in order to obtain larger pellets. T.harzianum was grown on MM (minimal medium) which was the YNB (Yeast Nitrogen Base medium) of Wickerham and Burton [12] with glucose as carbon source. Flasks were inoculated with spores $\left(1 \times 10^{7}\right.$ spore $\left./ \mathrm{mL}\right)$ and incubated at $30{ }^{\circ} \mathrm{C}$ in a $150 \mathrm{rpm}$ rotary shaker. S.cerevisiae was grown until reaching the log phase in a $150 \mathrm{rpm}$ rotary shaker on YPD broth media at $30^{\circ} \mathrm{C}$.

\subsubsection{Anaerobic fermentation}

The mycelial mass coming from aerobically grown cultures was added into the anaerobic fermentation media, which was the apple pomace hydrolysate. $40 \mathrm{~mL}$ hydrolysate was added into $50-\mathrm{mL}$ Erlenmeyer flasks in order to leave $20 \%$ of the culture flask volume as air space. Fermentation experiments were conducted for 5 days at $30{ }^{\circ} \mathrm{C}$. Samples were taken within certain time intervals, centrifuged at $6000 \mathrm{~g}$ for $15 \mathrm{~min}$. The supernatants were stored at $-18{ }^{\circ} \mathrm{C}$ for further analysis.

\subsection{Assays}

The amount of bioethanol in the supernatant was determined using HPLC (High Pressure Liquid Chromatography) equipped with $\mathrm{RI}$ (refractive index) detector and an Aminex HPX-87H column with an appropriate guard column (Bio-Rad, USA) at a flow rate of $0.6 \mathrm{~mL} / \mathrm{min}$. The temperatures of the column and detector were $60{ }^{\circ} \mathrm{C}$ and $50{ }^{\circ} \mathrm{C}$, respectively. The mobile phase was $5 \mathrm{mM} \mathrm{H}_{2} \mathrm{SO}_{4}$ filtered through $0.2 \mu \mathrm{m}$ filter and degassed.

The biomass represented as dry cell weight $(\mathrm{DCW}-(\mathrm{g} / \mathrm{L}))$ was determined by the gravimetric method. The total carbohydrate content of the samples (cell-free supernatant) was determined according to the phenol sulphuric acid method described by Dubois et al. [13]. The amount of carbohydrates was determined by using Varian Cary Bio 100 UV-Visible spectrophotometer at $490 \mathrm{~nm}$ against the blank. The total reducing sugar amount was determined according to the assay given by Somogyi [14]. The absorbance was read on Varian Cary Bio 100 UV-Visible spectrophotometer at $500 \mathrm{~nm}$ against water. 
Furfural (F) and hydroxymethlyfurfural (HMF) were determined using the same technique used for bioethanol determination.

In all experiments, kinetic parameters were estimated at maximum values obtained during the course of the fermentation with respect to bioethanol production. The following parameters were determined: yield of ethanol on substrate $\left(\mathrm{Y}_{\mathrm{P} / \mathrm{S}}\right)$, defined as $g$ of ethanol per $g$ of initial reducing sugar consumed; biomass yield on substrate $\left(\mathrm{Yx}_{/ \mathrm{S}}\right)$, defined as $\mathrm{g}$ of biomass per $\mathrm{g}$ of initial reducing sugar consumed; yield of ethanol on biomass $\left(\mathrm{Y}_{\mathrm{P} / \mathrm{X}}\right)$, defined as $\mathrm{g}$ of ethanol per $g$ of biomass; and volumetric productivity ( $\left.Q_{p}\right)$, defined as $g$ of ethanol produced per unit volume per unit time.

\subsection{Statistical design of experiments}

Design Expert Version 7.0.0 was used for the statistical experimental design for all the fermentation experiments with the response as bioethanol production $(\mathrm{g} / \mathrm{L})$.

\subsubsection{Determination of the inoculation time}

In order to determine the inoculation time of the microorganisms, general factorial design was used. Factors were designated as inoculation time of T.harzianum, A.sojae and S.cerevisae with five levels $(0 \mathrm{~h}, 24 \mathrm{~h}, 48 \mathrm{~h}, 72 \mathrm{~h}$ and $96 \mathrm{~h})$. In order to make the experiments more practical, designs were separated into two parts. For the first design, T.harzianum was inoculated into the flasks at 0 th $\mathrm{h}$. The other two organisms were combined with each other. And for the second design, A.sojae was inoculated into the flasks at the beginning and remaining organisms were combined with each other. Total of 50 experiments were conducted with 2 replicas of each factorial combinations for both designs.

\subsubsection{Screening of fermentation parameters}

2-level full factorial design was used in order to identify important parameters in the screening analysis. The factors were inoculation rate of A.sojae, T.harzianum and S.cerevisiae, ranging for each between 2 and $20 \%(\mathrm{w} / \mathrm{v})$, aeration (vented or sealed) and agitation speed (0-200 rpm). Total of 40 experiments were conducted with 8 center points. Since after aerobic growth, large amount of mycelial mass was formed which made the total mycelial mass addition into the fermentation flask impossible, inoculation rates of microorganisms were expressed as percentage $(\% \mathrm{w} / \mathrm{v})$. In fact these were kept in a broad range in order to catch any possible effect on bioethanol production. After aseptic inoculation of the mycelial mass from aerobic fermentation, plastic paraffin film was used to seal the flasks which provided strictly anaerobic conditions, whereas vented flasks allowed small amounts of gases $\left(\mathrm{O}_{2}\right.$ and $\left.\mathrm{CO}_{2}\right)$ to pass in and out through a silicone tube packed tightly with cotton.

\subsubsection{Optimization steps for bioethanol production}

A FCCD (face centered central composite design) (Table 2) was generated and conducted with three factors; which were inoculation rate of A.sojae $\left(\mathrm{X}_{1}\right)$ and inoculation rate of Tharzianum $\left(\mathrm{X}_{2}\right)$ ranging for each between $(0-6 \%)(\mathrm{w} / \mathrm{v})$ and agitation speed $\left(\mathrm{X}_{3}\right)$ ranging between 100 and $300 \mathrm{rpm}$. Total of 20 experiments were conducted with 5 center points for optimization experiments.

\section{Results and discussion}

\subsection{Apple pomace composition and hydrolysis}

The composition of apple pomaces varies according to the type of processing applied for juice extraction especially how many times the apples were pressed. According to the chemical compositional analysis shown in Table 1, initial reducing sugar for apple
Table 1

Compositional analysis of apple pomace (\%).

\begin{tabular}{lc}
\hline & Apple pomace \\
\hline Soluble ash in dry weight & $0.22 \pm 0.04$ \\
Insoluble ash in dry weight & $0.82 \pm 0.04$ \\
Total ash in dry weight & $1.04 \pm 0.01$ \\
Protein & $1.9 \pm 0.2$ \\
Total solids & $27.53 \pm 0.1$ \\
Soluble solids & $2.23 \pm 0.03$ \\
Insoluble solids & $25.30 \pm 0.03$ \\
Total dietary fiber & $32.54 \pm 0.5$ \\
Soluble dietary fiber & ${ }^{* *}$ \\
Insoluble dietary fiber & $11.24 \pm 0.2$ \\
Water activity (aw) $^{* *}$ & $25.24 \pm 1.0$ \\
Initial reducing sugar & $0.84 \pm 0.00$ \\
\hline
\end{tabular}

Notes: ${ }^{*}$ The values were the mean value of triplicated samples; ${ }^{* *}$ Involves protein (Dietary fiber $=$ solid - ash + protein $)$.

pomace was determined as $6.25 \%$ corresponding to $16.16 \mathrm{~g} / \mathrm{L}$. Furthermore its high amount of total solid content suggested that it might contain cellulose, hemicellulose and lignin in its solid fraction. In fact this was confirmed by the high amount of total dietary fibre content. HPLC results showed that arabinose was the main sugar in apple pomace [11]. The presence of fermentable sugars in apple pomaces in significant amounts, together with proteins, makes them potential candidates to be used for the production of value added bioproducts, such as bioethanol.

Hydrolysis that aims the opening of the accessible areas in the cellulose structure of lignocellulosic biomass by altering the macroscopic and microscopic size is an essential step to obtain fermentable sugars. Hydrolysis affects lignocellulose by creating larger accessible surface area and pore size, reducing the crystallinity, partially degrading the cellulose, increasing the solubility of hemicellulose and lignin and modifying the lignin structure. Moreover, any hydrolysis process should improve the formation of sugars or the ability to form them during the succeeding enzymatic hydrolysis, and avoid the degradation or loss of carbohydrate and formation of inhibitory byproducts for subsequent enzymatic hydrolysis and fermentation and be cost effective [15-17]. Based on this, apple pomace was hydrolysed with the phosphoric acid $\left(\mathrm{H}_{3} \mathrm{PO}_{4}\right)$ and neutralized with $\mathrm{NaOH}$. In fact the salt formed after this process was sodium phosphate, which remained in the hydrolysate to be used as nutrient by microorganisms. Therefore, a filtration operation was not needed with the consequent advantages: the improvement of process profitability (avoiding salts removal and decreasing the amount of nutrients needed for fermentation) and positive impact to the environment (the salt formed was not a waste) [18]. F and HMF are fermentation inhibitory byproducts of pentose and hexose sugars. According to HPLC results, $\mathrm{F}$ or HMF could not be detected in the apple pomace hydrolysates. The lack of furfural formation was most probably due to the stability of arabinose. Since HMF and F are inhibitory to fermentation, absence of these inhibitory products exhibited great advantage for efficiency of forthcoming fermentations.

\subsection{Results of statistical design of experiments}

The fermentation of cellulosic biomass to bioethanol directly has long been a desired goal. Some filamentous fungi have some advantages; (i) they can be directly inoculated onto cellulosic biomass as they do not require strictly anaerobic conditions, (ii) their filamentous growth habit facilitates separation of cell mass from the broth, (iii) the inoculation of non-sterile biomass is more practical since many fungal strains produce large numbers of conidiospores, which can be useful for inoculation demanding high 
Table 2

Face centered central composite design (FCCD) used in the optimization step with respect to bioethanol production (g/L).

\begin{tabular}{|c|c|c|c|c|}
\hline \multirow[t]{2}{*}{ Run no } & \multicolumn{3}{|l|}{ Actual level of variables } & \multirow{2}{*}{$\frac{\text { Response variable }}{\text { Bioethanol concentration }(\mathrm{g} / \mathrm{L})}$} \\
\hline & Inoculation rate of A.sojae (\%) & Inoculation rate of T.harzianum(\%) & Agitation speed (rpm) & \\
\hline 1 & 3 & 3 & 200 & 8.636 \\
\hline 2 & 6 & 0 & 300 & 5.262 \\
\hline 3 & 6 & 6 & 300 & 7.333 \\
\hline 4 & 6 & 6 & 100 & 3.783 \\
\hline 5 & 0 & 3 & 200 & 3.998 \\
\hline 6 & 3 & 3 & 200 & 8.748 \\
\hline 7 & 0 & 6 & 300 & 5.963 \\
\hline 8 & 3 & 3 & 200 & 7.505 \\
\hline 9 & 0 & 0 & 100 & 3.659 \\
\hline 10 & 0 & 6 & 100 & 5.006 \\
\hline 11 & 3 & 0 & 200 & 8.398 \\
\hline 12 & 6 & 0 & 100 & 3.840 \\
\hline 13 & 3 & 3 & 200 & 7.246 \\
\hline 14 & 6 & 3 & 200 & 7.824 \\
\hline 15 & 0 & 0 & 300 & 4.463 \\
\hline 16 & 3 & 3 & 300 & 6.109 \\
\hline 17 & 3 & 3 & 100 & 3.807 \\
\hline 18 & 3 & 3 & 200 & 7.408 \\
\hline 19 & 3 & 3 & 200 & 7.003 \\
\hline 20 & 3 & 6 & 200 & 6.459 \\
\hline
\end{tabular}

levels [8]. In this study Trichoderma harzianum and Aspergillus sojae, which were able to ferment cellulose or several sugars to bioethanol were chosen besides the yeast, S.cerevisiae, because of aforementioned advantages. This way, in addition to initial reducing sugars, remaining cellulosic compounds in hydrolysates could be fermented into bioethanol as well. A pre-growth cycle was applied in order to increase bioethanol production by enhancing the mass of mycelia used in the fermentation.

Inoculation time of the coculture is one the important parameter that needs to be considered in order to obtain high amounts of bioethanol. Results (data not shown) indicated that the inoculation of T.harzianum and A.sojae at the beginning ( 0 th $\mathrm{h}$ ) and inoculation of S.cerevisiae at the 24th $\mathrm{h}$ of fermentation gave the highest amounts of bioethanol $(7.42 \mathrm{~g} / \mathrm{L})$. Therefore, these inoculation times were fixed and used in further experiments.

In this present study a $2^{5}$ factorial design was used in the screening step in order to decrease the number of factors for the optimization step and set the levels into a more specific range. The ranges of the process parameters were described in Section 2.5.2. According to the results, maximum bioethanol production $(8.27 \mathrm{~g} /$ L) was obtained at $4 \%(\mathrm{w} / \mathrm{v})$ inoculation rate of A.sojae, T.harzianum and S.cerevisiae (\% v/v), high agitation speed (200 rpm), vented aeration method and 3 days of incubation. ANOVA results indicated that the constructed model was significant $(\mathrm{p}<0.01)$ with a $\mathrm{p}$-value of 0.0074 , and the most important factors affecting bioethanol production were two main factors; inoculation rate of A.sojae $\left(\mathrm{X}_{1}\right)$, agitation speed $\left(\mathrm{X}_{5}\right)$ and the interaction terms; inoculation rate of A.sojae and T.harzianum $\left(\mathrm{X}_{12}\right)$, inoculation rate of S.cerevisiae and aeration ( $\left.\mathrm{X}_{34}\right)$, inoculation rate of A.sojae, Tharzianum and agitation $\left(\mathrm{X}_{125}\right)$, inoculation rate of A.sojae, S.cerevisiae and aeration $\left(\mathrm{X}_{134}\right)$, inoculation rate of T.harzianum, S.cerevisiae and aeration $\left(\mathrm{X}_{234}\right)$, inoculation rate of A.sojae, T.harzianum, S.cerevisiae and agitation $\left(\mathrm{X}_{1235}\right)$ and inoculation rate of A.sojae, T.harzianum, aeration and agitation $\left(\mathrm{X}_{1245}\right)$. However, $\mathrm{p}$-values indicated that inoculum rate of T.harzianum $\left(\mathrm{X}_{2}\right)$ and S.cerevisiae $\left(\mathrm{X}_{3}\right)$ and aeration $\left(\mathrm{X}_{4}\right)$ were not significant factors whereas some of their interactions were significant, thus removing nonsignificant factors from the model were not hierarchical. Since, optimization of five factors would be very difficult in practice, factors were evaluated by examining the variety of graphs (Fig. 1) in order to find if some of them could be fixed or not. Examining these graphs, it was observed that low inoculation rate of A.sojae led to higher bioethanol concentration than high inoculation rate when the inoculation rates of T.harzianum and S.cerevisiae were fixed at their low levels, agitation speed was high and the vented flasks were used (Fig. 1a). Agitation speed was an important factor for bioethanol production. The higher the agitation speed the higher was the bioethanol production (Fig. 1b).

The effect of inoculation rate of S.cerevisiae was investigated in many reports [19]. The maximum bioethanol yield was obtained at $10 \%$ inoculation rate in the study conducted by Neelakandan and Usharani [20]. In this mixed culture fermentation study, it was found that low inoculation levels of S.cerevisiae led to effective bioethanol production. The relation between the inoculation rates of S.cerevisiae with respect to bioethanol production demonstrated that bioethanol production was high at the low level of inoculation rate of S.cerevisiae, when inoculation rates of A.sojae and T.harzianum were low, agitation speed was high and vented flasks were used (Fig. 1c). When inoculation rates of A.sojae and T.harzianum were changed to high levels (other parameters were the same), high bioethanol concentrations was obtained at low inoculation levels of S.cerevisiae. Although aeration was a nonsignificant term according to the model, its interactions were significant (Fig. 1d). Therefore it could not be removed from the model due to the hierarchy principle. The use of vented flasks led to higher bioethanol concentrations than the sealed flask. Since microorganisms favoured mild conditions and not strictly anaerobic conditions, this was an expected result.

Overall, as it can be seen from Fig. 1e, low levels of inoculation rates of A.sojae, T.harzianum and S.cerevisiae, high agitation speed and the use of vented fermentation flasks led to high bioethanol production. Therefore, the inoculation rate of S.cerevisiae was kept at its low level (4\%) by taking into account the model graphs shown in the foregoing figures. Although aeration was a nonsignificant model factor, with the use of vented flasks bioethanol production increased. Based on these, inoculation rate of S.cerevisiae was fixed at $4 \%(\mathrm{v} / \mathrm{v})$ and vented aeration method was chosen for the further optimization study.

Optimization of bioethanol production from apple pomace was performed according to the face centered central composite experimental design. According to the screening results, levels of the factors chosen for the optimization process were redefined. Inoculation rate of A.sojae and Tharzianum and agitation speed 


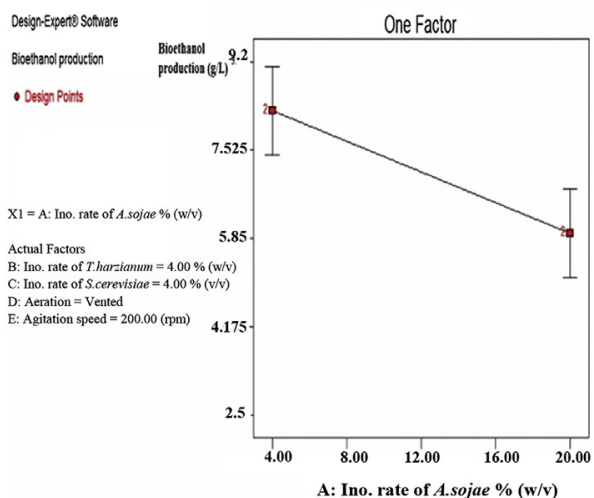

a)

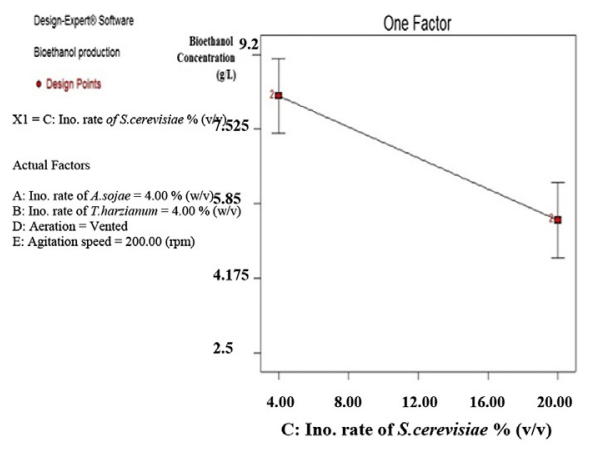

c)

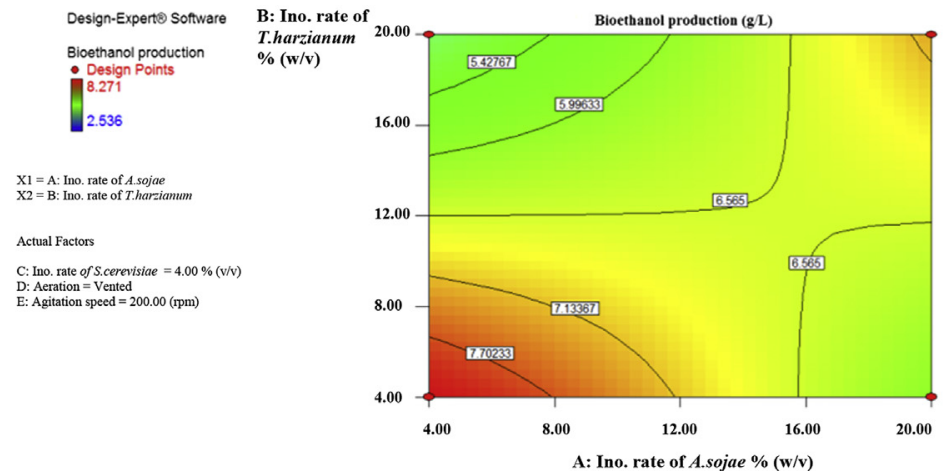

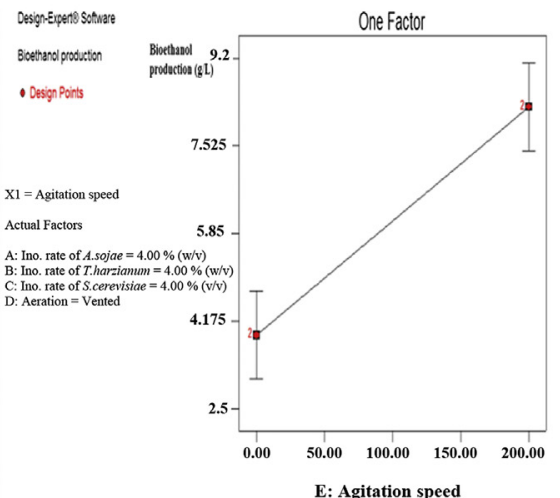

b)

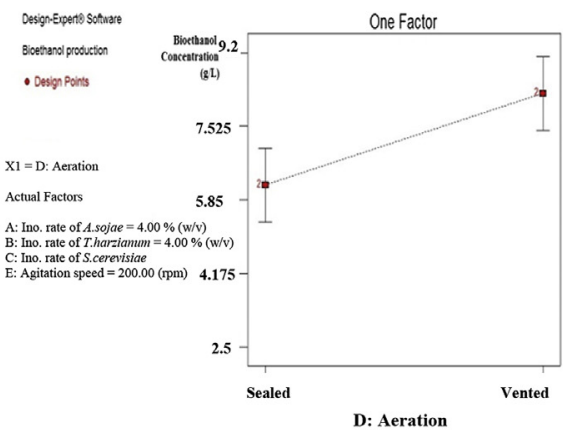

d)

A: Ino. rate of $A$. sojae $\%$ (w/v)

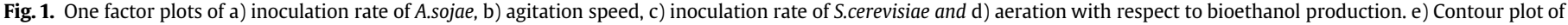
inoculation rates of A.sojae and T.harzianum.

were broadened in the range of $0-6 \%(\mathrm{w} / \mathrm{v}), 100-300 \mathrm{rpm}$ respectively. The actual levels of these variables and the responses are tabulated in Table 2. The p-value of the model, according to ANOVA, was 0.0063 which indicated that the constructed model was significant $(\mathrm{p}<0.01)$ and that the terms included in this model had an important effect on bioethanol production. This p-value also showed that although the results seemed close to each other they were different and statistically significant. The model equation that expressed bioethanol production in terms of coded factors was as followings:

$$
\begin{aligned}
\text { Bioethanol production }(\mathrm{g} / \mathrm{L})= & +7.32+0.50 * \mathrm{X}_{1}+0.29 * \mathrm{X}_{2} \\
& +0.90 * \mathrm{X}_{3}+0.40 * \mathrm{X}_{1} * \mathrm{X}_{3} \\
& +0.29 * \mathrm{X}_{2} * \mathrm{X}_{3}-2.40 * \mathrm{X}_{3}^{2}
\end{aligned}
$$

where $\mathrm{X}_{1}$ was inoculation rate of A.sojae, $\mathrm{X}_{2}$ was inoculation rate of T.harzianum, and $\mathrm{X}_{3}$ was agitation speed that constitute the significant factors effective on bioethanol production. As depicted in Fig. 2, higher concentrations of inoculation rates of Tharzianum and A.sojae 6\% (w/v) and agitation speed around $200 \mathrm{rpm}$ led to maximum amount of bioethanol. On the other hand inoculation rate of S.cerevisiae and aeration method did not change bioethanol production, significantly.

\subsection{Validation}

In order to validate the adequacy of the model equation a total of three verification experiments were carried out at the predicted optimum conditions for bioethanol production. The results showed $12.46,2.17$ and $12.21 \%$ deviation, respectively. The overall margin of error was $8.95 \%$. 
a)
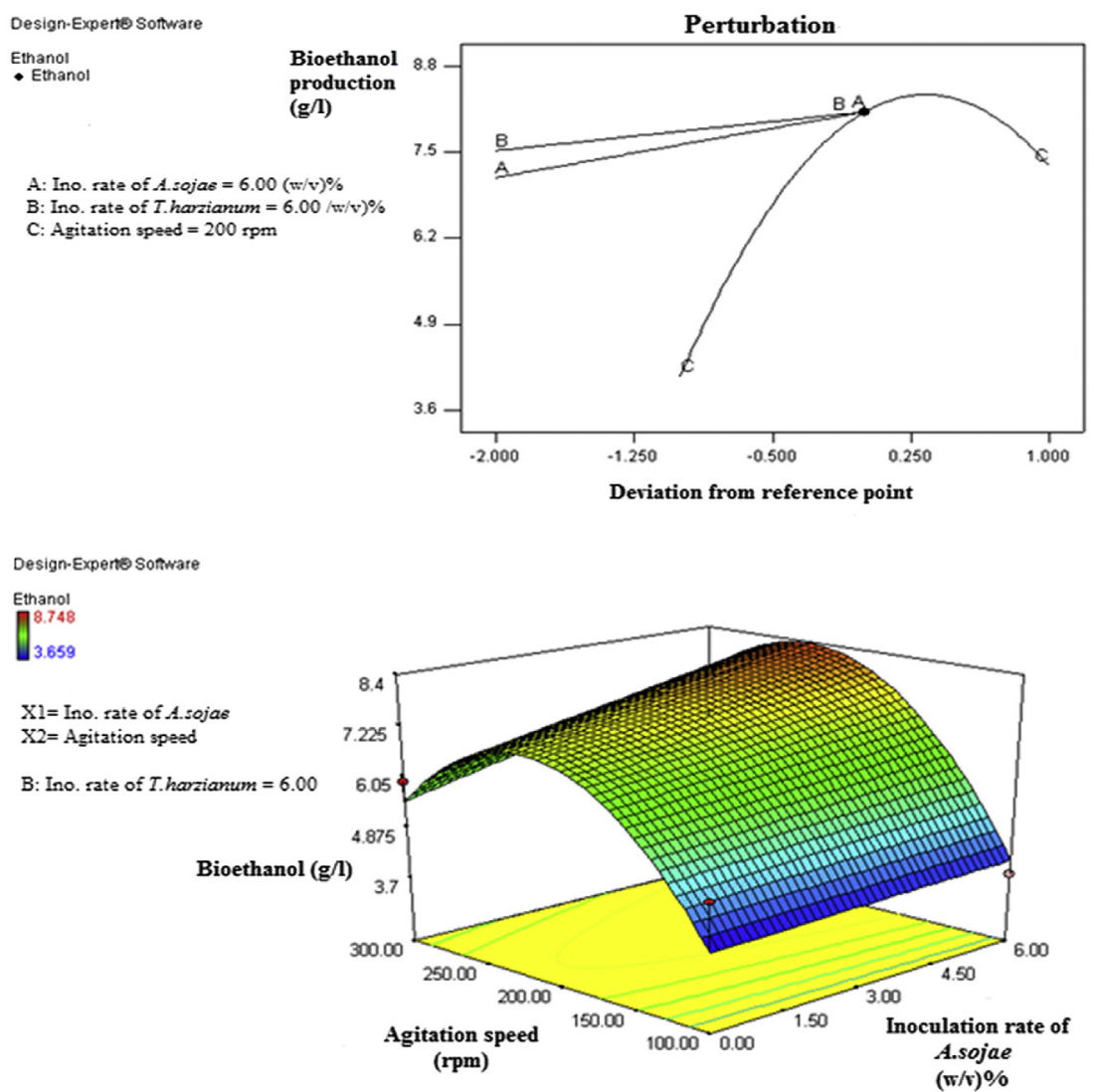

b)

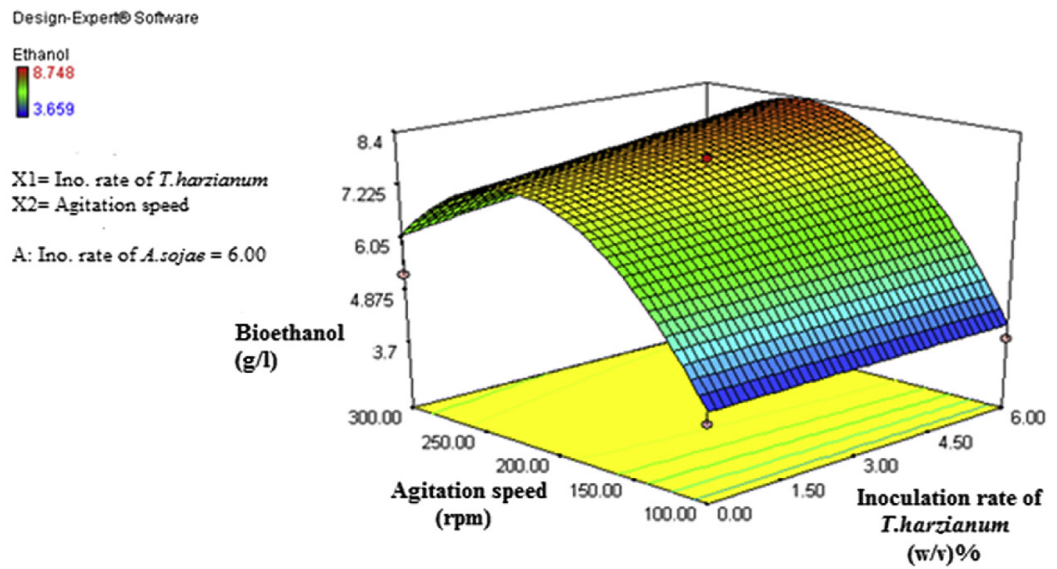

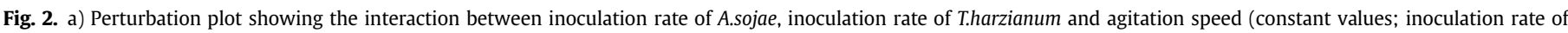

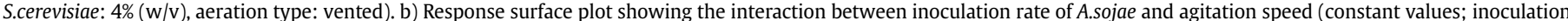

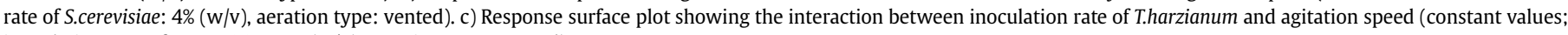
inoculation rate of S.cerevisiae: $4 \%(\mathrm{w} / \mathrm{v})$, aeration type: vented).

The yield factors and productivity results of the experiments performed in the optimization step are tabulated in Table 3. According to this table, maximum bioethanol yield on total reducing sugar content was obtained in the 6th experiment as $0.945 \mathrm{~g} / \mathrm{g}$ where the corresponding volumetric bioethanol productivity and bioethanol yield on biomass were $0.121 \mathrm{~g} / \mathrm{L} / \mathrm{h}$ and $1.673 \mathrm{~g} / \mathrm{g}$, respectively. This value was one of the highest obtained during all the runs. The fermentation profile corresponding to this set of experiments presented an increasing trend in bioethanol production making a peak $(8.75 \mathrm{~g} / \mathrm{L})$ at the $100 \mathrm{~h}$ of fermentation. Fig. 3a and $\mathrm{b}$ shows the initial sugar and initial carbohydrate utilization of the fermentations having different microbial combinations. All apple pomace hydrolysates had $16.16 \mathrm{~g} / \mathrm{L}$ of initial reducing sugar and $42.27 \mathrm{~g} / \mathrm{L}$ of initial carbohydrate in the first day of fermentation, respectively. It was observed that the microorganisms were using the sugars in the hydrolysates and breaking down the cellulose into sugars simultaneously. According to the literature, bioethanol production was influenced by using cocultures [19]. Employing mixed culture fermentation in this study was very effective on efficient bioethanol production. The best result was obtained when the three cultures were used together. When the three organisms were inoculated into the fermentation flasks, maximum bioethanol 
Table 3

Maximum yield factors and productivity results of the optimization step with respect to bioethanol production obtained during the course of the fermentation.

\begin{tabular}{|c|c|c|c|c|}
\hline \multirow[t]{3}{*}{ Run No } & EtOH yield & EtOH yield & Biomass yield & Volumetric EtOH \\
\hline & On biomass & On substrate & On substrate & Productivity \\
\hline & $\left(\mathrm{Y}_{\mathrm{P} / \mathrm{X}}\right)^{*}$ & $\left(\mathrm{Y}_{\mathrm{P} / \mathrm{S}}\right)^{*}$ & $\left(Y_{X / S}\right)^{*}$ & $\left(Q_{p}\right)^{*}$ \\
\hline 1 & 1.003 & 0.867 & 0.864 & 0.090 \\
\hline 2 & 0.434 & 0.389 & 0.896 & 0.085 \\
\hline 3 & 0.690 & 0.604 & 0.876 & 0.076 \\
\hline 4 & 0.758 & 0.541 & 0.714 & 0.124 \\
\hline 5 & 0.412 & 0.544 & 1.321 & 0.042 \\
\hline 6 & 1.673 & 0.945 & 0.565 & 0.121 \\
\hline 7 & 0.332 & 0.681 & 2.050 & 0.062 \\
\hline 8 & 0.675 & 0.714 & 1.058 & 0.078 \\
\hline 9 & 1.192 & 0.490 & 0.411 & 0.093 \\
\hline 10 & 1.117 & 0.732 & 0.655 & 0.052 \\
\hline 11 & 0.943 & 0.791 & 0.839 & 0.087 \\
\hline 12 & 0.665 & 0.518 & 0.779 & 0.106 \\
\hline 13 & 0.713 & 0.576 & 0.808 & 0.075 \\
\hline 14 & 0.797 & 0.551 & 0.691 & 0.081 \\
\hline 15 & 1.276 & 0.577 & 0.452 & 0.046 \\
\hline 16 & 0.589 & 0.456 & 0.773 & 0.064 \\
\hline 17 & 0.587 & 0.564 & 0.961 & 0.093 \\
\hline 18 & 0.612 & 0.712 & 1.164 & 0.077 \\
\hline 19 & 1.006 & 0.687 & 0.683 & 0.105 \\
\hline 20 & 0.801 & 0.585 & 0.730 & 1.152 \\
\hline
\end{tabular}

* $\mathrm{Y}_{\mathrm{P} / \mathrm{X}}$ (gEtOH/gbiomass); $\mathrm{Y}_{\mathrm{P} / \mathrm{S}}$ (gEtOH/gsubstrate); $\mathrm{Y}_{\mathrm{X} / \mathrm{S}}$ (gbiomass/gsubstrate); Qp (gEtOH/L/h).

concentration reached $8.75 \mathrm{~g} / \mathrm{L}$, while it reached only $4.46 \mathrm{~g} / \mathrm{L}$ maximum bioethanol concentration when only S.cerevisiae was inoculated. It seemed that the fermentation flasks with the cocultures showed an efficient mass transfer, since initial sugar decreased very fast during the course. Thus, the microorganisms were able to use all of the initial sugars and brake down the

\section{Reducing Sugar Profile $(g / L)$}

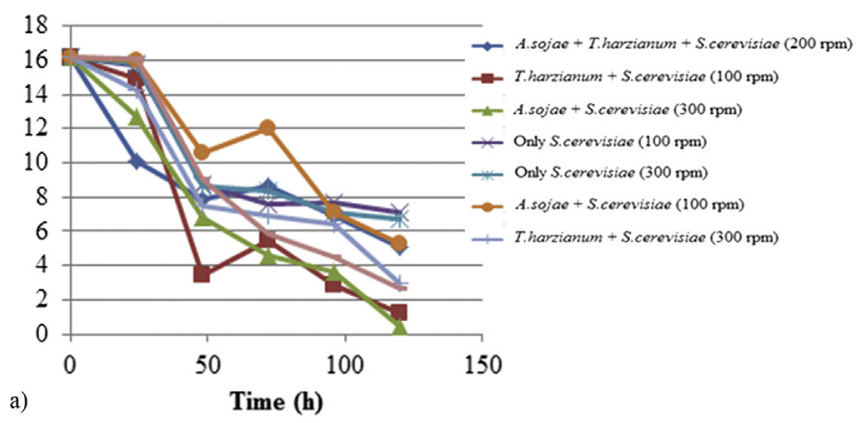

Total Carbohydrate Profile (g/L)

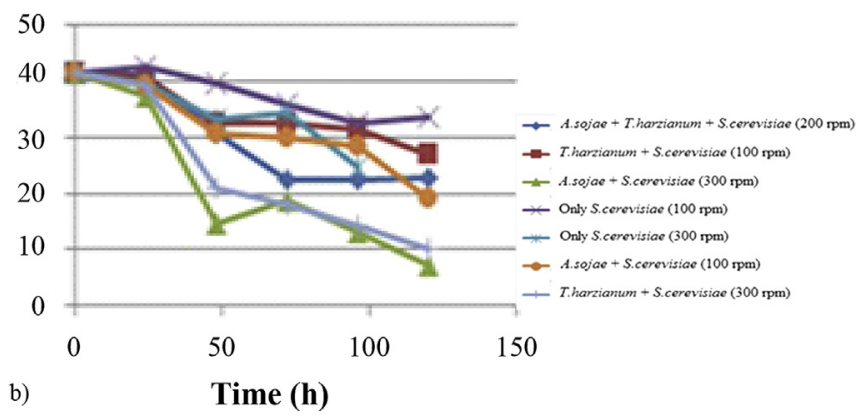

Fig. 3. a) Reducing sugar consumption profile and b) total carbohydrate consumption during the course of fermentation experiments in the optimization step. cellulose molecules into sugars more effectively because of a better mass transfer and little $\mathrm{O}_{2}$ access through silicone tubing (vented aeration method). However, in the fermentation flasks which had only S.cerevisiae, reducing sugar consumption was not very high. In fact the yeast did not have the ability to use arabinose, which was the major sugar in the apple pomace hydrolysate.

Bioethanol production from agro-industrial wastes has raised interest within recent years because of their suitability as low-cost alternative to replace fossil fuels. Mostly agro-industrial wastes [21-24] such as palm-oil mill effluent [21], cheese whey, and potato peel waste [23], pineapple cannery waste [24], rice straw [25], orange peel [26], grape pomace [27], apple [28] and cashew apple juice [29] were used in bioethanol production. Hence, current study will serve as a starting point for the use of apple pomace, in further coculture fermentation studies.

Many researchers have reported on the production of bioethanol from a wide variety of strains and agro-industrial wastes under optimized conditions. Arapoglou et al. [23] presented a new form of potato peel waste hydrolysis with a specific combination of enzymes and hydrochloric acid, subsequently fermented by Saccharomyces cerevisiae var. bayanus to enhance bioethanol production. According to their results, $18.5 \mathrm{~g} / \mathrm{L}$ reducing sugar was released and $7.6 \mathrm{~g} / \mathrm{L}$ bioethanol was produced after fermentation. The maximum bioethanol production in our study was nearly 1.2 times higher than the bioethanol production obtained by Arapoglou et al. [23]. Moreover, orange peels were used as fermentation raw material for bioethanol production [26]. Bioethanol yields of $0.25 \mathrm{~g} / \mathrm{g}$ on a biomass basis, $0.46 \mathrm{~g} / \mathrm{g}$ on a substrate basis were obtained which are quite lower than the ones found in the current study.

Even though bioethanol production is common among certain species, filamentous fungi are not well known for their abilities. Numerous fungi are able to produce low concentrations of bioethanol compared to S.cerevisiae, under $\mathrm{O}_{2}$ limited conditions. Many of them have various enzymes such as xylanase, cellulase and amylase complexes that enable the simultaneous saccharification and fermentation with one organism. Stevenson and Weimer [8] screened the environment for fungal strains capable of this conversion when grown on minimal medium and it was observed that a member of the genus Trichoderma isolated from cow dung was able to produce $0.4 \mathrm{~g} / \mathrm{L}$ bioethanol initially. In another study conducted by Skory et al. [9] bioethanol producing filamentous fungi were screened by testing nineteen Aspergillus species for their efficiency of converting glucose, xylose and cellulose to bioethanol, it was found that one strain, Aspergillus oryzae, reached nearly $100 \%$ theoretical bioethanol yield from $50 \mathrm{~g} / 1$ glucose. In the study of Karimi et al. [25] Mucor indicus, Rhizopus oryzae, and S. cerevisiae were investigated and compared with pure cellulose for the production of bioethanol. They determined that R.oryzae had the best bioethanol yield (74\%) followed by M.indicus (68\%), levels lower than the maximum bioethanol yield obtained in the current study.

The results obtained from optimization studies demonstrated that mixed culture fermentation, which contained all of the microorganisms, was required for effective bioethanol production. In literature there are various studies related to mixed (co) culture fermentations $[29,30]$. The direct fermentation of cellulosic biomass to bioethanol has long been a desired goal. Production of bioethanol via direct bioconversion process from palm-oil mill effluent generated by the oil-palm industries was studied by Alam et al. [21]. The bioethanol production was carried out with mixed cultures such as T. harzianum, Phanerochaete chrysosporium, Mucor hiemalis and S. cerevisiae. According to their results, the mixed culture of T.harzianum and S.cerevisiae yielded the highest bioethanol production which was in accordance with our results. Patle and Lal [28] reviewed some bioethanol producing strains isolated 
from raw honey, molasses and rotten fruits such as grapes, apple and sapota. Their usability for bioethanol production was investigated using mixed culture of Zymomonas mobilis and Candida tropicalis. They suggested that these wastes proved to be promising substrates for bioethanol production. Sharma et al. [19] also studied some fermentation parameters such as inoculum rate, temperature, incubation and agitation time on bioethanol production from kinnow waste and banana peels by simultaneous saccharification and fermentation using cocultures of $S$. cerevisiae $G$ and Pachysolen tannophilus MTCC 1077. Temperature of $30^{\circ} \mathrm{C}$, inoculation rate of S.cerevisiae $G$ of $6 \%(\mathrm{v} / \mathrm{v})$ and of P.tannophilus of $4 \%(\mathrm{v} / \mathrm{v})$, incubation time of $48 \mathrm{~h}$ and agitation time of $24 \mathrm{~h}$ were determined as the optimum conditions at which $26.84 \mathrm{~g} / \mathrm{L}$ bioethanol was produced.

Feedstocks based on corn and sugarcane are of the greatest interest for ethanol production. Sindhu et al. [31] reported that $0.685 \mathrm{~g} / \mathrm{g}$ of reducing sugar was produced per gram of pretreated biomass using sugarcane tops as feedstock for the production of bioethanol. The two-step enzymatic hydrolysis of corn meal by commercially available $\alpha$-amylase and glucoamylase and the subsequent or simultaneous ethanol fermentation of the hydrolysates by $S$. cerevisiae were studied by Mojović et al. [32]. According to their results, the maximum value of product yield on substrate $\left(\mathrm{Y}_{\mathrm{P} /}\right.$ s) was $0.50 \mathrm{~g} / \mathrm{g}$. Another study conducted by Gutiérrez-Rivera [33] aimed increasing ethanol production and the complete utilization of hydrolysate sugars using sugarcane bagasse hydrolysate supplemented with sugarcane molasses in a mixed yeast culture ( $S$. cerevisiae ITV-01 and Scheffersomyces (formerly Pichia) stipitis NRRL Y-7124), achieved $0.45 \mathrm{~g} / \mathrm{g}$ ethanol yield. In these two studies, yields on substrate were lower than the maximum bioethanol yield $(0.945 \mathrm{~g} / \mathrm{g})$ obtained in the current study.

\section{Conclusion}

Bioethanol was produced from low-cost agro-industrial waste product, apple pomace reaching maximum bioethanol concentration using cocultures which showed better sugar and carbohydrate consumption profile. The presence of fungi in the fermentation flasks caused more effective sugar utilization because of their ability to use both pentoses and hexoses. Inoculation rates of $6 \%(\mathrm{w} /$ v) for A.sojae and T.harzianum and $4 \%(\mathrm{w} / \mathrm{v})$ for S.cerevisiae were determined as the optimum conditions with the vented aeration method and agitation speed of $200 \mathrm{rpm}$ that gave the highest bioethanol concentration and ethanol yield on total reducing sugar content $\left(\mathrm{Y}_{\mathrm{P} / \mathrm{S}}\right)$ as $8.748 \mathrm{~g} / \mathrm{L}$ and $0.945 \mathrm{~g} / \mathrm{g}$, respectively. To date to the best of our knowledge, no reports are available in the literature regarding the use of T.harzianum, A.sojae and S.cerevisiae together for bioethanol production. Therefore, this study will serve as a base line of the initial studies in this field. Furthermore, the results pointed out that using cocultures can be an effective way of producing bioethanol because of their synergistic interactions. Also utilization of apple pomace for production of bioethanol can lead the way of producing value added products from similar agroindustrial wastes and provide an alternative solution to the accumulation of lignocellulosic wastes which is a primary environmental problem of the fruit juice industry.

\section{Acknowledgement}

Authors are thankful to the Department of Food Engineering at Izmir Institute of Technology (IZTECH) for providing the required elements of this research and to Paul J. Weimer from USDA-ARS-US Dairy Forage Research Center, Madison, United States and Molecular Biology Laboratory of IZTECH for the kind supply of the strains.

\section{References}

[1] Pinilla L, Torres R, Ortiz C. Bioethanol production in batch mode by a native strain of Zymomonas mobilis. World J Microbiol Biotechnol 2011;27:2521-8.

[2] Ibeto CN, Ofoefule AU, Agbo KE. A global overview of biomass potentials for bioethanol production: a renewable alternative fuel. Trends Appl Sci Res 2011;6(5):410-25.

[3] Balat M, Balat $\mathrm{H}$, Öz C. Progress in bioethanol processing. Prog Energy Combust Sci 2008;34:551-73.

[4] AIJN European Fruit Juice Association: Market Report - Liquid Fruit. [http:/ www.aijn.org/pages/main/file.handler?f=AlJNMarketReport2010.pdf]

[5] Joshi VK, Attri D. Solid state fermentation of apple pomace for the production of value added products. Nat Prod Rad 2006;5(4):289-96.

[6] FAO Statistical Database. http://faostat3.fao.org/browse/Q/QC/E; 2011.

[7] FAO Statistical Database. http://faostat.fao.org/site/368/DesktopDefault.aspx? PageID=368\#ancor; 2011 .

[8] Stevenson DM, Weimer PJ. Isolation and characterization of a Trichoderma strain capable of fermenting cellulose to ethanol. Appl Microbiol Biotechnol 2002;59:721-6.

[9] Skory CD, Freer SN, Bothast RJ. Screening for ethanol-producing filamentous fungi. Biotechnol Lett 1997;19(3):203-6.

[10] Xu Q Singh A, Himmel ME. Perspectives and new directions for the production of bioethanol using consolidated bioprocessing of lignocellulose. Curr Opin Biotechnol 2009;20:364-71.

[11] Ucuncu C, Tari C, Demir H, Buyukkileci AO, Ozen B. dilute-acid hydrolysis of apple, orange, apricot and peach pomaces as potential candidates for bioethanol production. J Biobased Mater Bio 2013;7(3):376-89.

[12] Wickerham LJ, Burton KA. Carbon assimilation tests for the classification of yeasts. J Bacteriol September 1948:56(3):363-71.

[13] Dubois M, Gilles KA, Hamilton JK, Rebers PA, Smith F. Colorimetric method for determination of sugars and related substances. Anal Chem 1956;28(3):350-6.

[14] Somogyi M. Notes on sugar determination. J Biol Chem 1952;195:19-23.

[15] Margeot A, Hahn-Hagerdal B, Edlund M, Slade R, Monot F. New improvements for lignocellulosic ethanol. Curr Opin Biotechnol 2009;20:372-80.

[16] Chandel AK, Chan E, Rudravaram R, Narasu ML, Rao LV, Ravindra P. Economics and environmental impact of bioethanol production technologies: an appraisal. Biotechnol Mol Biol Rev 2007;2(1):14-32.

[17] Sanchez OJ, Cardona CA. Trends in biotechnological production of fuel ethanol from different feedstocks. Bioresour Technol 2008:99:5270-95.

[18] Gámez S, Gonzalez-Cabriales JJ, Ramirez JA, Garrote G, Vazquez M. Study of the hydrolysis of sugar cane bagasse using phosphoric acid. J Food Eng 2006;74:78-88.

[19] Sharma N, Kalra K, Oberoi HS, Bansal S. Optimization of fermentation parameters for production of ethanol from kinnow waste and banana peels by simultaneous saccharification and fermentation. Indian J Microbiol 2007;47:310-6.

[20] Neelakandan T, Usharani G. Optimization and production of bioethanol from cashew apple juice using immobilized yeast cells by Saccharomyces cerevisiae. Am-Euras J Sci Res 2009;4(2):85-8.

[21] Alam MZ, Kabbashi NA, Hussin SNIS. Production of bioethanol by direct bioconversion of oil-palm industrial effluent in a stirred-tank bioreactor. J Ind Microbiol Biotechnol 2009;36:801-8.

[22] Antoni D, Zverlov VV, Schwarz WH. Biofuels from microbes. Appl Microbiol Biotechnol 2007;77:23-35.

[23] Arapoglou D, Varzakas T, Vlyssides A, Israilides C. Ethanol production from potato peel waste (PPW). Waste Manage 2010;30:1898-902.

[24] Nigam J. Continuous ethanol production from pineapple cannery waste. J Biotechnol 1999;72:197-202.

[25] Karimi K, Emtiazi G, Taherzadeh MJ. Ethanol production from dilute-acic pretreated rice straw by simultaneous saccharification and fermentation with Mucor indicus, Rhizopus oryzae, and Saccharomyces cerevisiae. Enzyme Microb Technol 2004;40(1):138-44.

[26] Oberoi HS, Vadlani PV, Madl RL, Saida L, Abeykoon JP. Ethanol production from orange peels: two-stage hydrolysis and fermentation studies using optimized parameters through experimental design. J Agric Food Chem 2010:58:3422-9.

[27] Korkie L, Janse B, Viljoen-Bloom M. Utilising grape pomace for ethanol production. S Afr J Enol Vitic 2002;23(1):31-6.

[28] Patle S, Lal B. Ethanol production from hydrolysed agricultural wastes using mixed culture of Zymomonas mobilis and Candida tropicalis. Biotechnol Lett 2007;29:1839-43.

[29] Pinheiro ÁDT, Rocha MVP, Macedo GR, Goncalves LRB. Evaluation of cashew apple juice for the production of fuel ethanol. App Biochem Biotechnol 2008; 148:227-34.

[30] Keating J, Robinson J, Cotta M, Saddler J, Mansfield S. An ethanologenic yeast exhibiting unusual metabolism in the fermentation of lignocellulosic hexose sugars. J Ind Microbiol Biotechnol 2004;31:235-44.

[31] Sindhu R, Kuttiraja M, Binod P, Janu KU, Sukumaran RK, Pandey A. Dilute acid pretreatment and enzymatic saccharification of sugarcane tops for bioethanol production. Bioresour Technol 2011;102(23):10915-21.

[32] Mojović L, Nikolić S, Rakin M, Vukasinović M. Production of bioethanol from corn meal hydrolyzates. Fuel 2006;85(12-13):1750-5.

[33] Gutiérrez-Rivera B, Ortiz-Muñiza B, Gómez-Rodríguez J, Cárdenas-Cágala A González JMD, Aguilar-Uscanga MG. Bioethanol production from hydrolyzed sugarcane bagasse supplemented with molasses "B" in a mixed yeast culture. Renew Energ 2015;74:399-405. 